\title{
News / Information
}

\section{The Entrepreneurship Education and Research Network among the Universities of Central and Eastern Europe (ERENET)}

\section{Report on the Activities}

The Entrepreneurship Education and Research Network among the Universities of Central and Eastern Europe ERENET, consists of university academicians, government representatives, experts from business services providers and responsible entrepreneurs, aiming at contribution to the promotion of entrepreneurship at the university curricula, harmonisation and development of entrepreneurial education, evaluation and development of government's SME national policies, promotion of communication and dissemination of best practices in SME promotion related issues. The aims of ERENET are:

$>$ Creation of a network of professors, lecturers, scientists from CEE to work together in order to create common Central European set of values

$>$ Exchange of university curriculum, lecturers and later students

$>$ Launching joint research projects

$>$ Organizing workshops, seminars on entrepreneurship

$>$ Preparing joint Internet periodical

\section{Membership}

In 2006 ERENET had 36 Members from 16 countries representing 29 institutions. At the time of the $2^{\text {nd }}$ ERENET Annual Meeting the membership consisted of 55 Members from 23 countries. Today ERENET has 90 members representing 44 universities, 3 ministerial authorities, 20 business service providers and 3 international organizations.

\section{Peoject development}

1. Project on strategies of the development of entrepreneurship and SME sector in the Black Sea Economic Cooperation Region

This project was launched within the framework of the Permanent International Secretary of the Organization of the Black Sea Economic Cooperation (PERMIS BSEC) with financial assistance of the Turkish Representative of the Konrad Adenauer Foundation and the technical assistance of the ERENET.

Since the launch of the initiative of the BSEC in 1992, it has evolved into a fullfledged regional organization in 1999 with the Permanent International 
Secretariat based in Istanbul and supported by the Black Sea Trade and Development Bank based in Thessalonica. Now it has 12 members - Albania, Armenia, Azerbaijan, Bulgaria, Georgia, Greece, Moldova, Romania, Russia, Serbia, Ukraine and Turkey. The core element of the political and economic transformation of any country in transition is the creation of a sound private sector and further development of SME \& entrepreneurship. These are considered as the principal driving forces in economic development. In order to assist to analyse the SME sector development in the BSEC region, especially in the transition economies as well as in the new or associated EU countries, the PERMIS BSEC and Konrad Adenauer Stiftung decided to organize a high-level policy meeting on achievement and task in the entrepreneurship and SME development policies to be held at the end of 2007 at the BSEC Headquarters in Istanbul. This project aims at elaboration of the background document for this meeting.

The Project was oriented towards the Development of Entrepreneurship and SME Sector Policies in the BSEC Region and by elaborating a background and discussion paper supporting a High-level Meeting of the National SME Focal Points and representatives of invited national donor institutions and international organizations for setting the direction and tasks for entrepreneurship policies, especially in the transition economies of the BSEC region, including support within the framework of the Good Neighbouring Policies of the EU and other donor support programmes.

ERENET Experts prepared and presented a report on the current SME sector in the BSEC countries following a methodology agreed with BSEC PERMIS and KAS. Country presentations included the following:

$>$ Presentation of the SME sector development;

$>$ Legislation and steps of doing business;

$>$ SME Support Infrastructure;

$>$ Financing SMEs;

$>$ Tasks for improvement and further development of the SME sector;

$>$ SWOT analysis of the SME sector presenting the Strength-Weakness Opportunities-Threats.

Country presentations were prepared by the following ERENET Experts:

$>$ Prof. Dr. Dejan Eric, School of Economics at the University of Belgrade and the Belgrade Banking Academy, General Manager of Institute of Economic Science, the Republic of Serbia;

D Dr. Dilek Çetindamer, Associate Professor, Graduate School of Management, Sabancı University, Istanbul, Turkey; 
> Mr. Umut Yilmaz CETINKAYA, Ph.D. Candidate, Anchora Consultancy, Science and Technology Policies Research Center, Middle East Technical University (METU), the Republic of Turkey;

$>$ Dr. Irina Naoumova, Associated Professor at the University of Tennessee, Khoxville, USA and at the State University-Higher School of Economics within the EMBA Program, Moscow;

> Mrs. Anna Petrosyan, Ph.D. in Economics, Chief Specialist, Department of Small and Medium Entrepreneurship (SME) Development, Ministry of Trade and Economic Development, the Republic of Armenia;

$>$ Prof. Alakbar Mammadov, President of the National Confederation of Entrepreneurs (Employers) Organizations, the Republic of Azerbaijan;

$>$ Dr. Antal Szabo, UN ret. Regional Adviser, Scientific Director of ERENET, Corvinus University of Budapest, Hungary.

The Workshop on "Strategies of the Development of Entrepreneurship and SME Sector in the Black Sea Economic Cooperation Region" was held in Istanbul on 22-24 November 2007.

The Konrad Adenauer Foundation published the material prepared by the ERENET team titled "Strategies for the Development of Entrepreneurship and the SME sector in the Black Sea Economic Cooperation region", Ankara, 2008, ISBN: 978-975-7968-74-0.

\section{Project on benchmarking of entrepreneurship education in selected EU and North-American Countries}

The purpose of the project was to collect current practice in entrepreneurship education at the Romanian universities as well as collect best practices and curriculums in entrepreneurship education in the old, new and associated EU countries as well as in North-America in order to develop and establish an advance similar education in the country too. The objectives of the present project were elaborated by the academic staff of Management-Economics Department of Petru Maior University of Targu-Mures. The project wishes to gather information in the field of investigation and implementation of the entrepreneurial education in the Romanian universities, specialised institutions of Romania and European Union to create an international research network and to elaborate a project within the Programme Framework 7.

This project was coordinated by As. Prof. Zsuzsanna Katalin Szabó, Dean of the Faculty of Economics, Juridical and Administrative Sciences at the Petru Maior University of Targu-Muresh (Romania) in cooperation with Dr. Antal Szabó, Scientific Director of ERENET.

As part of the Project, the findings and national country studies were presented and discussed within the framework of the $3^{\text {rd }}$ International Conference on 
Economics, Law and Management Conference - ICELM - held on 4-7 June 2008 at the Petru Maior University. The following ERENET members prepared presentation to this Conference:

$>$ Education for Entrepreneurship from Kindergarten to Adult Learning Dr. Antal Szabó, UN ret. Regional Adviser, Scientific Director of ERENET, Budapest/Hungary

$>$ Student's Entrepreneurial Attitudes and Entrepreneurship Education in 14 Countries - Dr. László Szerb, Associate Professor, University of Pécs, Faculty of Business and Economics, Hungary

$>$ Entrepreneurship Education in Croatia - Dr. Sc. Sania Pfeifer, Associate Professor of Management, Faculty of Economics, J.J. Strossmayer University, Osijek, Croatia

$>$ Entrepreneurship Education at the Hungarian Universities from Bachelor via entrepreneurial incubating to Ph.Degree - Prof. Péter Szirmai, Head of Small Business Development Centre, and Katalin Szakács, PhD Student, Corvinus University of Budapest, Hungary

$>$ Teaching Entrepreneurship in Hungary - Krisztián Csapó, Assistant Professor, and Attila Pethoe, Assistant Professor, Corvinus University of Budapest, Hungary

$>$ Entrepreneurship Education in Poland - Professor Dr. Krzysztof Wach, Cracow University of Economics, Poland

$>$ Entrepreneurship Education in Slovakia - Dr. Vincent Šoltés, Associated Professor, Faculty of Economics, Technical University of Košice, Slovakia

$>$ Canadian Entrepreneurial Education - Dr. Laurence Hewick, Hewick Research Inc., Burlington, Canada

$>$ Entrepreneurship Education in France - Dr. Million Jean-Claude *, I.U.T Louis Pasteur 67300 Schiltigheim, France

> Entrepreneurship Education in Germany - Dr. Hans-Jürgen Weissbach, Professor Fachhochschule, University of Applied Sciences Institute for Entrepreneurship, Frankfurt am Main, Germany

$>$ Entrepreneurship and Social Responsibility - Madi Sharma *, Chief Executive, MADI Group, The Ethnic Trail, UK, and European Economic $\&$ Social Committee, Brussels, Belgium

$>$ Can Business Education Alter Cultural Norms? - Jim Lavon Finlay *, Lebanese American University, Lebanon

> Developing Entrepreneurship in Romanian Tourism Business - Cristina R. Coloisteanu *, Academy of Economics Studies Bucharest, Romania 
Remarks: Experts marked by * are not ERENET Members

The main papers of the Conference, conclusions and recommendations of the Round Table held as part of the ICELM3 see at ERENET PROFILE Vol.III. No.11. (http://www.erenet.org/publications/profile11.pdf). Further papers will be published in the ERENET PROFILE Vo.IV.No.13 to be issued in January 2009.

\section{ERENET PROFILE}

ERENET successfully launched its Internet periodical ERENET PROFIL. The aim and purpose of the periodical is to enhance local and regional understanding of the possibilities offered by small and medium enterprise. It is equally directed to encouraging cooperation among experts who are concerned with entrepreneurship, small and medium enterprise research and the necessary education and training required to encourage economic development across Europe.

For the ERENET Annual Meeting it was decided to issue a special publication devoted to our first jubilee celebrating the tenth issue of ERENET PROFILE. In the meanwhile the $11^{\text {th }}$ publication, devoted to entrepreneurship education, was issued. Some 700 pages on entrepreneurship development, education, the SME sector, business services providers, institutions, events and expert profiles and more have been explored. Unfortunately this compilation due to its size could not be web-site at http://www.erenet.org.

ERENET PROFILE has been received an international recognition through obtaining an ISSN code 1789-624X. This has been registered in Paris. In addition to this ERENET got a compliment for the US Congress Library that "this periodical is one of the best sources of information on entrepreneurship development in Central and Eastern Europe".

\section{Cooperation with other networks}

International organizations and initiatives have been discovered ERENET. Discussions have been started in order to create synergy among few initiatives in CEE.

\section{European Small Business Alliance (ESBA) http://www.esba-europe.org/}

ESBA is a non-party political group which cares for entrepreneurs and the selfemployed and represents them through targeted advocacy and profiling activities. ESBA also works towards the development of strong, independent advocacy and benefits groups in all EU countries. ESBA is welcomed the Entrepreneurship and Research and Education Network of Central European Universities (ERENET) as a new Pan-European Member. 
The European Commission has launched its proposal for a Small Business Act for Europe demonstrating the recent improvement in the attention paid to the needs of small businesses by EU and national policy makers. Many challenges lay ahead, however, in order for entrepreneurs feel the tangible benefits of the EU's SME policy. Therefore, ESBA look forward to sharing our experiences of the key topics of entrepreneurship education and business services providers and to learning from the significant expertise of ERENET's members in September.

ESBA inaugurated its $10^{\text {th }}$ years anniversary in Brussels. ERENET was invited too. Since 1998, ESBA has become one of the major SME organizations in Europe, representing almost 1 million small businesses in 36 European countries. However, due to lack of financial resources we could not attend in this important event.

ESBA and ERENET agreed to exchange information and send to each other all relevant information. We highly appreciate the issue of the ESBA Bulletin with ESBA views on EU news and views on entrepreneurship.

\section{2. idisc - infoDev Incubator Support Center http://www.ecabit.org}

ECAbit incubators and technology parks network aims to add value to its members' activities by fostering and strengthening innovation and entrepreneurship support, exchanging information and knowledge, collaborating among incubators and entrepreneurs in the ECA region and on global level, and disseminating knowledge about national SME and innovation development policies and programs. See ERENET became a Member of the ECAbit, which stands for Eastern European and Central Asian Business Incubators and Technology Parks Network. At time being, ECAbit counts 30 full members from 15 countries, including associations from Russia, Uzbekistan, Kyrgyz Republic and the Ukraine representing about 180 incubators.

\section{Dr. Antal Szabó}

Scientific Director of ERENET

UN retired Regional Adviser on Entrepreneurship and SMEs 


\section{Call for Papers \\ International Journal of Emerging Markets \\ Special Issue:}

Changing Patterns of Global Growth

Deadline: 31 January 2009

The credit crunch, increases in food prices and the oil crisis have all led to great uncertainty in the global economy. However, some countries have achieved higher growth whereas standards of living have been predicted to plummet in other economies. A special issue of International Journal of Emerging Markets sets out to analyse the following themes:

$>$ The role of India, China and other emerging markets in insulating world economic growth from US financial crisis

$>$ How the US financial crisis is affecting emerging markets

$>$ Strategies for companies from emerging markets on how to cope with the current crisis

> Is there a role for China and India and other emerging economies in insulating the global economy?

$>$ Should policies be domestic or global?

$>$ How should emerging markets cope with the global financial crisis?

\section{Types of paper:}

Both empirical as well as theory building papers will be considered. As the topic lies at the intersection of several scholarly domains, papers can draw from several different fields such as organisation theory, strategy, international business, technology and invasion management and business law. Aspects can also encompass other areas including entrepreneurship, operations research and organisational behaviour.

\section{Submission guidelines and timeline:}

All manuscripts should be prepared according to the author guidelines located at: www.emeraldinsight.com/ijoem.htm. All papers will be double blind reviewed following the journal's normal review procedure.

Submissions to International Journal of Emerging Markets must be made using the ScholarOne Manuscript Central system: http://mc.manuscriptcentral .com/ijoem.

Deadline for submissions: 31 January 2009 
The guest editors for the special issue are John McManus and David Floyd. Please direct any enquiries to Dr McManus at jmcmanus@lincoln.ac.uk.

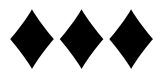

\section{Call for Papers}

\section{International Journal of Technology and Globalisation Special Issue:}

\section{Emerging Markets}

\section{Deadline: 30 July 2009}

\section{Guest Editors:}

Prof. Rajesh K Pillania, Management Development Institute, India.

Prof. Maria Alejandra Gonzalez-Perez, Universidad Eafit, Colombia.

\section{Need and Significance of the Topic:}

With a high growth rate and still significant untapped potential, emerging markets are the growth engines of the world economy. Globalization and technology are two prime drivers of the global economy. Innovations have become popular again and globalization of research and development is taking place. Emerging markets are becoming source of low cost research and development initiatives on the one hand and at the same time these markets need technology for the developmental needs. How to face the changing realities of technology globalization requires substantial strategic thought, guidance and implementation. Contributions are invited on various aspects of technology globalization and emerging markets.

A Suggested List of Topical Areas: A list of suggested topics includes but is not limited to the following:

Rise of Emerging Markets

$>$ Globalization of R\&D

$>$ Technology for Emerging Markets

$>$ Technology Transfer Issues in Emerging Markets

Innovations in Emerging Markets

$>$ Innovations Policy in Emerging Markets

Innovations for Bottom of Pyramid Markets

$>$ Future of Technology Globalization and Emerging Markets 
The International Journal of Technology and Globalisation (IJTG) provide a refereed and authoritative source of analysis on the interactions between technological innovation and globalisation. It serves as an international forum for exchange of ideas and views on the global implications of technology for economic growth, sustainable development and international security. IJTG publishes original and practical contributions. These can be quantitative or qualitative, surveys, reviews or cases studies, or research notes up-to-date with current research in the field. Journal Webpage https://www.inderscience.com /browse/index.php?journalID=104.

\section{Schedule:}

Deadline for Submission of Papers: July 30, 2009

Expected Publication Date: December 2009

\section{Contact information:}

Professor Rajesh K Pillania

E-Mail: r_pillania@yahoo.com

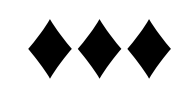

\section{Call for Papers}

\section{European Journal of Cross Cultural Competence and Management (EJCCM)}

About EJCCM (European Journal of Cross Cultural Competence and Management):

EJCCM is the official scholarly publication of the International Association of Cross-Cultural Management and Competence (IACCM) (http://iaccm.wuwien.ac.at/). The journal aims to widen and deepen the discussion about issues regarding the influence of cultural differences and diversity on the management of organisations of all kinds. Of particular relevance is the question of how culture affects both managers and decision-makers in situations involving the cross-cultural transfer of knowledge, values and experiences.

The scope of EJCCM is further widened by a close cooperation with the European chapter of the Society of Intercultural Education Training And Research (SIETAR Europa).

\section{Objectives:}

EJCCM covers the broad field of cross-cultural research with special reference to management in practice. One of its main objectives is the establishment of a platform for the discussion of cultural issues in modern business across 
disciplines and cultures. In the spirit of its founding organisation, EJCCM encourages contributions from different fields of science dealing with the interrelations and links between culture, personality and patterns of behaviour; with the effects of culture and cultural differences on intercultural interactions and of interactions on cultural difference, with learning from successful and not so successful intercultural action, with strategies of cultural adjustment, hybridisation, and with cultural distinction and separation. The journal explicitly encourages papers about the dynamics of cross-cultural interactions during the transition in East, Central and South East Europe, the former Soviet Union, and Newly Independent States.

\section{Readership:}

EJCCM offers insights into the effects of culture on business in a globalised world, which are relevant for academics in business studies, social science and other fields of science dealing with culture, intercultural trainers and educators as well as business people working internationally. While the title of the journal puts a clear emphasis on studies from a European perspective, distinct nonEuropean perspectives are highly welcome, too.

\section{Contents:}

EJCCM publishes original papers, case studies, book reviews, management and conference reports. In a Practitioner's Corner, applied and practical contributions are included which are of particular relevance for educators, trainers and business people working in an international and multicultural context. Special Issues devoted to new developments in the field and other important topics in cultural research are encouraged.

\section{Specific Notes for Authors:}

Submitted papers should not have been previously published nor be currently under consideration for publication elsewhere.

All papers are refereed through a double blind process. A guide for authors, sample copies and other relevant information for submitting papers are available on the Submission of Papers web-page.

You may send one copy in the form of an MS Word file attached to an e-mail (details of file formats in Author Guidelines) to Dr. Frank Brueck (brueck@wuwien.ac.at), below, with a copy to: Editorial Office E-mail: editorial@inderscience.com and please include in your submission the title of the Journal.

As we move ahead with our preparations for the first year of EJCCM we developed a couple of ideas. We will appreciate any support which will help us to get you involved into EJCCM and IACCM activities.

(1) Given the close deadlines we thought it might be useful to envisage an inaugural issue 2009/01, which is setting the stage for our further publication policy of EJCCM. In the inaugural issue we want to trigger a discussion about 
developments in the field (state of the art, needs and direction of further research). If you want to contribute to this discussion in the inaugural issue we cordially invite you to send us a contribution of about 2,000 words by end of November. Of course, this discussion may go on for a little while and we also welcome contributions at a later date, which then will be published in follow up issues.

(2) Issue 2009/2-3 shall be devoted to state of the art articles in your fields of expertise. We cordially invite you to share your competence with EJCCM readers. For the 2009/2-3 issue articles of about 7,000 - 8,000 words (flexibility is given) should be submitted by January 15, 2009 at latest. Of course, any contribution at a later point of time is also highly welcome. For issue 2009/4 the regular deadline is March 1, 2009. More on deadlines you will find below.

(3) Considering the expertise of IACCM members and our cooperating colleagues we cordially invite you to submit proposals for special issues of EJCCM. Because of the envisaged work load we suggest that teams of two or three scholars undertake the effort. In many cases special issues are related to conferences. While this is perfectly all right we indicate that we always would like to see a separate open call, because some knowledgeable scholars might not be in a position to attend a specific conference but would be willing and able to submit good papers independently. You may suggest any related focus and deadline.

For a full issue you would have to submit 7 revised papers (about 7000-8000 words each) and the two double blind reviews of these papers. A shorter special section (3-5 papers) is also possible. 


\title{
Call for Papers
}

\section{IJBEM Conference}

\section{Competition or Cooperation: East vs. West}

\author{
12 - 13 May 2009
}

\section{Edmonton. Canada}

With the rapidly changing landscape of the global economy as the backdrop to a more challenging and unpredictable world, it is imperative to look at cooperative and competitive antecedents for future East-West relationships and the internal economic, social and political evolution of both markets. For example, following China's 2001 accession to the World Trade Organization (WTO), the country has quickly risen to become the world's third largest trading economy (with total trade exceeding US\$1.1 trillion). China will soon replace Canada as the United States' largest trading partner. The rise of Eastern countries, most notably China and India, and the displacement of industry in the West raises the basic question: Is the East a competitive or cooperative partner in trade, investment and business relations?

Fearful observers suggest that the East will overtake the West as a center for business and economic development. Optimists, on the other hand, see complementary relations between the two regions. The reality is that the East is currently undergoing a major socio-political and economic transformation, providing both opportunities and challenges for regional stability, sustainable development, and international business. To further explore contrasting economic environments and business relations between the two regions, we seek submissions generally relating to:

$>$ Political, regulatory, economic and business relations between the East and the West

$>$ Entry modes and performance of Western companies in the East, and vice versa

> Comparative studies of management, management education, and entrepreneurship

> Foreign Direct Investment (FDI) and trade between the East and the West

$>$ The impact of Eastern business internationalization on the West

$>$ Political and institutional change in the East and its impact on the West

$>$ Family ownership, state-owned ownership and internationalization

$>$ Corporate social responsibility, strategic management, and marketing practices 
Case studies and industry reports linking the East to the West

Please submit abstracts to: Ilan Alon ialon@rollind.edu and William Wei weix@macewan.ca by Dec. 15, 2008. Authors of accepted abstracts will need to submit a full paper by Feb. 15, 2009. Selected paper will be eligible for publication in a Special Issue coming out of the conference. A pre-conference trip to Alberta Oil Sands http://oilsands.alberta.ca will be subsidized for conference presenters/attendees.

\section{Organizers and Sponsors:}

> MacEwan School of Business, Edmonton, Canada

$>$ Rollins College, The China Center and the Crummer Graduate School of Business

$>$ International Journal of Business and Emerging Markets (IJBEM)
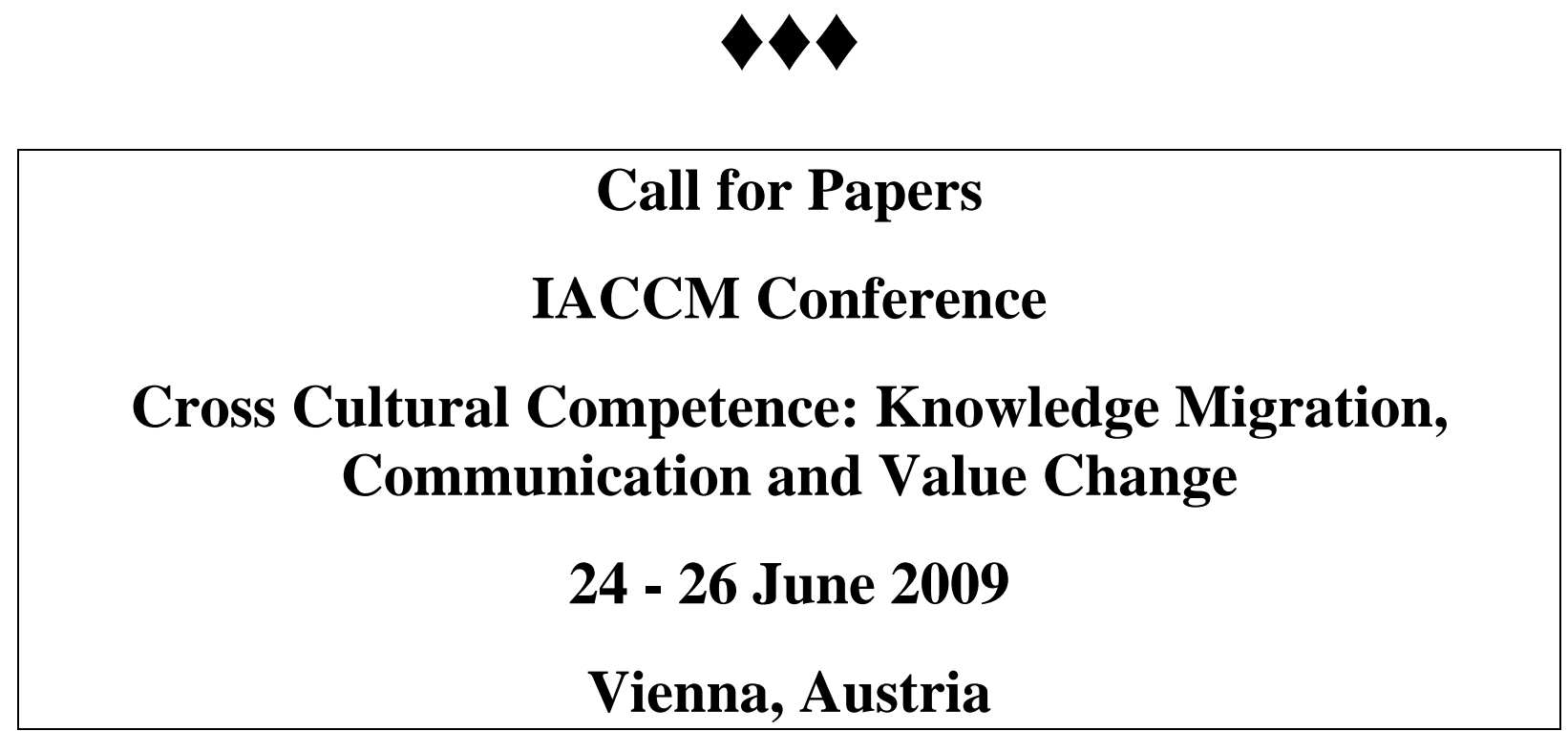

Some 15 years ago we laid the foundations of IACCM with the mission to promote young European scholars in the field of cross cultural management and competence. Meanwhile several of those young scholars made career. We are glad to note that they are still with us and willing to share their knowledge and expertise with the next generation of young scholars.

There were times when we managed to raise huge funds to implement our mission, but there are also times when means are scarce, and we cordially thank all those who contributed to our continuous efforts. For IACCM 2008 many thanks are due to the Poznan University College of Business and Foreign Languages and Peter Odrakiewicz and Hubert Paluch as the local organizers.

As to the IACCM 2009 doctoral seminar and annual meeting we have fixed the main theme 'Cross Cultural Competence: Knowledge Migration, 
Communication and Value Change' and the date June 24 IACCM doctoral seminar, June 25-26, IACCM 2009 conference.

The event will take place in Vienna, and more will follow soon.

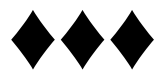

\begin{tabular}{|c|}
\hline Call for Papers \\
IX Chemnitz East Forum \\
Conflicts, Frictions and Paradoxes in CEE Management \\
$10-12$ September 2009 \\
Chemnitz, Germany
\end{tabular}

The Chemnitz East Forum provides a platform for the exchange of research on processes of societal transformation in Central and East European countries and its impact on states and organizations in the Western hemisphere. We would like to invite research papers dealing with all aspects of organizational conflicts, frictions and paradoxes with respect to management in CEE countries.

We prefer theory-based empirical studies, but also welcome papers of a theoretical or conceptual nature or with a focus on methodological issues in this context. The conference topics include (but are not limited to):

Management mistakes and managing mistakes in CEE

$>$ Clashes between Western Management and Eastern Reality

$>$ Frictions of transferred and established management concepts and practices

$>$ Inappropriate leadership behaviour and its consequences

$>$ Paradoxes of entrepreneurship in Post-Soviet societies

$>$ Success and failure of management strategies and their implementation

$>$ Industrial relations, tariff negotiations and conflicts in CEE firms

$>$ Resistance and deviant behaviour in CEE firms

$>$ Ethical problems and corporate responsibility in CEE management.

We particularly encourage young researchers and $\mathrm{PhD}$ students to submit papers.

Please send an attached file (doc, rtf) of an extended abstract (1,500 words) to the organizing committee via e-mail. Abstracts should contain the author(s) 
name(s), title and position, institution, address, phone and fax numbers as well as e-mail address.

Submissions should be received by 28 February 2009. Authors will be notified of the outcome of their submission by 31 March 2009. In the event of your paper being accepted, you should be prepared to submit a full paper by $\mathbf{3 1}$ July.

For further information please visit our conference homepage www.tuchemnitz.de/wirtschaft/bw15/konferenzen/ostforum.

The conference fee is 150 Euro. If possible, participants from East European countries will have the conference fee and their travel and accommodation expenses refunded. Further details will be sent together with an invitation to participate in the Forum.

Please submit your abstract via email to: Irma.Rybnikova@wirtschaft.tuchemnitz.de. 